\title{
An Analysis of the Obstacles and Countermeasures in the Implementation of Talent Policy in Resource-Based Cities - Based on the Study of Hegang City, the Coal City
}

\author{
Fuyan Hong*, Shiming Zhang
}

\author{
Harbin University of Commerce, Harbin, Heilongjiang, China \\ *Corresponding author.Email:461629043@qq.com
}

\begin{abstract}
Hegang City in Heilongiiang Province is a typical resource-based city with relatively exhausted energy and relatively backward economy. Difficulties in the implementation of talent policy and stagnant talent work are the "bottleneck" that restricts the sound and rapid economic development of Hegang City. Therefore, how to innovate the talent policy and efficiently implement the talent policy is the stepping stone to Hegang's economic transformation. This article uses the SWOT analysis method to study the conclusions of internal and external difficulties affecting the implementation of the talent policy in Hegang City, and proposes the analysis of countermeasures for the transformation of the resource industry to develop the economy and the government to change the concept to focus on talents, in order to solve the problem of excessive resistance to the implementation of the talent policy in Hegang City.
\end{abstract}

Keywords: Resource-based city, talent policy, policy implementation

\section{INTRODUCTION}

The development or rise of resource-based cities mainly depends on the exploitation and utilization of natural resources (Hegang City, Heilongjiang Province is mainly mineral resources). In recent years, under the general background of the transition of the planned economic system, due to the continuous aging and backwardness of resource mining enterprises and excessive overdraft of resources, resource-based cities have encountered a series of problems, such as sluggish economic development, significant deterioration of the ecological environment, and huge number of laid-off workers. And so on, have seriously affected the local social stability, and even spread to the whole country. Therefore, the transformation of resource-exhausted cities is imminent, and the implementation effect of the talent policy is an important factor influencing the success of the transformation.

\section{CURRENT STATUS OF THE IMPLEMENTATION OF THE TALENT POLICY IN HEGANG CITY}

\subsection{The "Golden Crane Return to Work" Talent Introduction Policy is not Effective}

According to statistics from the Bureau of Human Resources and Social Security of Hegang City, since the implementation of the "Golden Crane Back to Gang" policy to introduce 100 graduate students in 2017, 107 graduate students (and above) were successfully introduced in 2017, 58 in 2018, and in 2019 Introduce 35 people. It can be seen that the number of people introduced has shown a significant decline and a sharp drop. According to the postgraduates working in Hegang, the situation of introducing talents is not optimistic. The number of recruits is far from the target number. Graduate students of the same age are not optimistic about the current economic development of Hegang City and did not regard Hegang City as Future development location. In addition, the human resources of Hegang City still have a series of problems such as small total talents, low talent quality, uneven talent structure, serious brain drain, and poor performance of talents. 


\subsection{The Overall Quality of Talents is not High}

From the perspective of talent density, as of 2019, Hegang has a total population of 1.108 million and a total of 76,570 talents, which is low compared with the number of talents per 10,000 people in neighboring cities; from the perspective of population education level, all The average number of years of education per capita in the province is greater than or equal to 9 years. Hegang City is less than the province's average level of 8.7 years, and the majority of people with a high school degree or below, mostly technical secondary school; from the perspective of talent structure, there are graduate students in the talent team 11990 people with a university degree, accounting for $1.1 \%$ of the city's total population. In the current countylevel party and government department, the original postgraduate degree accounted for $0.1 \%$, the bachelor degree accounted for $1.4 \%$, the junior college degree accounted for $11.7 \%$, and the technical secondary school degree. Accounted for $26.8 \%$, with a high school degree or below accounting for $50 \%$, and the cadre's educational background presents a triangular shape. Leading talents who play a major role in the economic development process are extremely scarce. Cadres with this structure will mostly rely on experience to deal with problems, and there is a certain gap between the current economic development and change of thinking.

In addition, starting from the age structure, talents over the age of 45 account for $28.3 \%$ of the total talents, and the age of talents is too large to cause a disruption in career continuity. The low proportion of young talents is also not conducive to the rapid development of business innovation; from the perspective of industrial distribution, the proportion of Hegang talents concentrated in science, education, culture and health is as high as $64.5 \%$, which can promote the development of social undertakings, but there is a shortage of economic talents. Skilled talents and rural practical talents accounted for only $4.7 \%$ and $0.9 \%$. The number of talents is far from meeting the needs of the "two bases and six industries"; the ratio of industrial talents to the first, second, and third output value ratio is 24:50:26. On the contrary, this kind of industrial structure distribution and talent industry distribution have little direct effect on economic development, and the advantages of talent economic development service function are not highlighted, which will have a negative impact on the economic development of Hegang City.

\subsection{Serious Brain Drain}

In recent years, the loss of talents in Hegang City has been serious, with a total of more than 10,000 talents lost. The reason is that the economically developed areas of Hegang City cannot satisfy the employment desire of college graduates. Lost talents through two-way selection in the talent market, transfer of talents, independent employment or development of entrepreneurship in other places, but less than 1,000 talents introduced through talent introduction policies such as "Golden Crane Return to Work", and the ratio of introduced to lost talents is less than 1. : 10, which is far from the reasonable limit of $2: 1$ for the return rate and detention rate during the economic take-off stage.

\section{RESISTANCE TO THE IMPLEMENTATION OF THE TALENT POLICY IN HEGANG CITY}

\subsection{External Resistance}

\subsubsection{Low level of economic development and low welfare benefits}

After the planned economic system transition, the number of laid-off workers in Hegang City has increased, resulting in an excessive financial burden on personnel expenditures, and structural and systemic contradictions cannot be ignored. Now the service industry is underdeveloped due to the lack of large and medium-sized enterprises and low profits and taxes. Historical and contemporary factors have led to a lack of momentum for economic development in this region, and there is a large gap between it and developed regions in terms of talent welfare allowances, housing subsidies, and social security. The survey shows that $65.5 \%$ of talents expect a monthly salary of more than 4,000 yuan, but only $40 \%$ meet the requirements. The long-term salary package does not match the ability, which is not conducive to fully mobilizing the enthusiasm and initiative of talents.

\subsubsection{Resource-based cities have a single structure and few industrial chains}

Hegang City is a resource-based city with a coal economy dominated by coal, with few non-coal industries. However, the low level of coal processing and the few industrial chains with a single structure are detrimental to the development of high-level talents. When urban transformation becomes an inevitable trend, with the gradual increase of various non-coal enterprises, the demand for high-tech talents, foreign economic and trade talents, tourism talents and other talents will definitely increase. Vigorously introduce and cultivate resourcesoriented cities. High-tech talents for economic development are the key to transformation. 


\subsubsection{The development environment is relatively backward}

From the perspective of location advantages, Hegang City is located in the remote northeast of my country, with inconvenient transportation and weak connections with surrounding cities; from the perspective of the entrepreneurial environment, unprincipled competition in some departments and positions has led to greater energy consumption and tight policy implementation. Therefore, although Hegang City has introduced some talent policies, due to the lack of foresight, scientificity and practicality, it seems that the results have been minimal.

\subsection{Internal Resistance}

\subsubsection{The willingness of graduates to return home is not strong}

Hegang City's compulsory education and basic education are in a good development situation. Each year, nearly 5,000 college students are sent to national colleges and universities, and the trend is increasing year by year, but the return rate of college graduates is extremely low. The reason is that the more developed areas of Hegang City are economically backward and weak, which does not meet the expectations and pursuits of college graduates in the city where they are employed; second, due to the influence of traditional concepts and the impact of the market, vocational and technical education is extremely backward, The training of technicians is paralyzed. Higher education has not played the role of local universities in promoting the economy.

\subsubsection{The quality of government services needs to be improved}

From the perspective of the government's emphasis, the government lacks a correct understanding of talent training, does not pay enough attention to the use of talents, and lacks proper long-term planning for talent capital investment. In the long run, the attraction to talents is weak and the total number of talents is small., The quality of talents is low, and the age is relatively aging; from the perspective of human resource environment, the arrangements for the relocation of talents, personnel relations, spouse placement, and children's schooling are not satisfactory; from the perspective of service quality, the service quality is poor and the work is done The efficiency is low, the relevant departments stick to the old rules and are accustomed to examination and approval, and do not pay much attention to publicity and interpretation.

\section{SUGGESTIONS ON THE IMPLEMENTATION OF THE TALENT POLICY IN HEGANG CITY}

\author{
4.1. Transform the Resource Industry to \\ Develop the Economy and Provide Strong \\ Motivation for Talents
}

\subsubsection{Develop the economy and promote industrial transformation and upgrading}

The Bureau of Mines should strive from all sides and actively create conditions to accelerate the construction of the Niaoshan Mine. The mine has a design capacity of 1.2 million tons, a prospective reserve of 380 million tons, a geological reserve of 220 million tons, and a carefully investigated reserve of 120 million tons. You can also consider going abroad to develop coal resources in neighboring Russia. The existing large-scale power plant, Xinhua Power Plant, has an installed capacity of 600,000 kilowatts in the first phase, and the tax provided accounts for $20 \%$ of the city. At present, the Hegang Mining Bureau is using sufficient electricity to produce carbon, and using the excess electricity, a carbon factory has been started from Shangzhi City to produce semi-finished products, and then the carbon electrification has been developed, with good benefits. In the future, cheap power can also be used to develop energy-intensive industries. Speed up the transformation of Nanshan Media Preparation Plant and develop briquette processing.

\subsubsection{Improve the environment and strengthen the comprehensive utilization of resources}

The industrial scale of making hollow bricks using coal ash from power plants can be expanded. On the one hand, considering that the country should ban the use of clay to make bricks in cities; on the other hand, considering that waste is turned into treasure, it can continue to expand in the future. Renovate and expand key enterprises such as Heyou Pesticide, Sanbao Group, Shenger Pharmaceutical, Harbin Beer Group, Longjiang Wine, Hualong Glass, Donghua Cement, Huaxin Paper and other key enterprises, and start discontinued enterprises. Make agricultural and sideline products processing industry play an important role in economic transformation. And vigorously promote the green agricultural project, accelerate the strategic adjustment of the rural economic structure, and focus on the development of green agriculture. The planting industry mainly adjusts the ratio of grain, economy, and feed, and emphasizes the development of rice, cash crops and feed. 


\subsubsection{Strengthen cooperation and open to the north for development}

Hegang is located in the northern border of the motherland, with a 28-kilometer border between Heilongjiang and Russia. The good relations between China and Russia can be used to carry out economic cooperation in plantation, mining, forestry, and tertiary industries. It is necessary to actively promote the construction of a bridge at Mingshan Port in Luobei County (on the border of Heilongjiang and Russia) to facilitate communication between the two sides.

\subsection{The Government Changes its Concept to Value Talents and Provide Talents with Development Space}

\subsubsection{Implement talent preferential treatment policies to attract talents and retain talents}

The external reasons for the brain drain and the lack of willingness to return home in Hegang City are the abundant development opportunities and wide employment channels in the economically developed areas; the internal reason is the gap between the ideals and pursuits of talents and reality. Proceeding from internal and external reasons, resource-based cities need to implement preferential treatment policies for talents, improve the material treatment of talents, and minimize the gap with developed cities. And follow the objective requirements of economic laws and attract talents with high welfare. In terms of welfare, the salary of 985 and 211 college graduates has been increased, and subsidies and relocation allowances of different levels have been given. For high-level experts who have introduced provincial government subsidies or above, the national and provincial government will provide 1:1 matching, etc.; in terms of living, housing subsidies will be provided to highlevel talents, and talents with outstanding contributions can be directly rewarded with an area of not less than 60 square meters A housing of meters. And establish the talent medical care card and the health file, organize the physical examination regularly.

\subsubsection{Innovate talent training model and improve the quality of introduced talents}

In response to the actual needs of resource-exhausted cities, Hegang City should focus on cultivating economic, skilled and rural practical talents, and strive to cultivate compound talents with strong working ability to make the talent team younger and vigorous. At the same time, it is necessary to strengthen financial investment in education, improve school conditions and supporting facilities, encourage and support students to invest in the transformation and construction of resource-exhausted cities, guide students to use their talents in pillar industries, and provide suggestions for upgrading the industrial structure.

\subsubsection{Strengthen the function of political socialization and strengthen policy propaganda}

Hegang City can publicize the talent policy more, expand its visibility, make full use of electronic media resources such as Weibo, WeChat platforms, web pages, and traditional media resources such as newspapers to publish and report the city's policy content, expand application channels, and select candidates excellent.

\section{CONCLUSION}

In summary, efficient implementation of talent policies and innovative talent policies is the key to promoting the transformation of resource-based cities. This article analyzes the internal and external resistance and draws two conclusions: the transformation of the resource industry is to develop the economy and the government to change the concept to provide the development space for talents, and to provide talent innovation countermeasures for the transformation of resource-based cities.

\section{REFERENCES}

[1] Liu Xiaowen, Shen Wanfang, Duan Peixin, Chen Xiaolan. Evaluation on the sustainable development and transformation of coal resource-exhausted cities in the new era [J]. China Mining Industry, 2020, 29(12): 7582.

[2] Zhu Jixuan. Research on the introduction of talents in resource-based cities [J]. Cooperative Economy and Technology, 2020(23): 98-99.

[3] Malin Song, Xin Zhao, Yuping Shang. The impact of low-carbon city construction on ecological efficiency: Empirical evidence from quasi-natural experiments. Resources, Conservation and Recycling, 2020, 157

[4] Sustainability Research - Sustainable Development; New Sustainable Development Study Results from China University of Mining and Technology Described (Integrated Evaluation of the Carrying Capacities of Mineral Resource-based Cities Considering Synergy between Subsystems). 22088939-7367-45fa-a4c4fb3df2b26805, 2020, 
[5] Daniel Sanchez-Serra. Talent and Creative

Economy in French Local Labour Systems.

Environment and Planning C: Politics and Space, 2014, 32(3):405-425.

[6] Evi Hartmann, Edda Feisel, Holger Schober. Talent management of western MNCs in China: Balancing global integration and local responsiveness. Journal of World Business, 2009, 45(2):169-178 